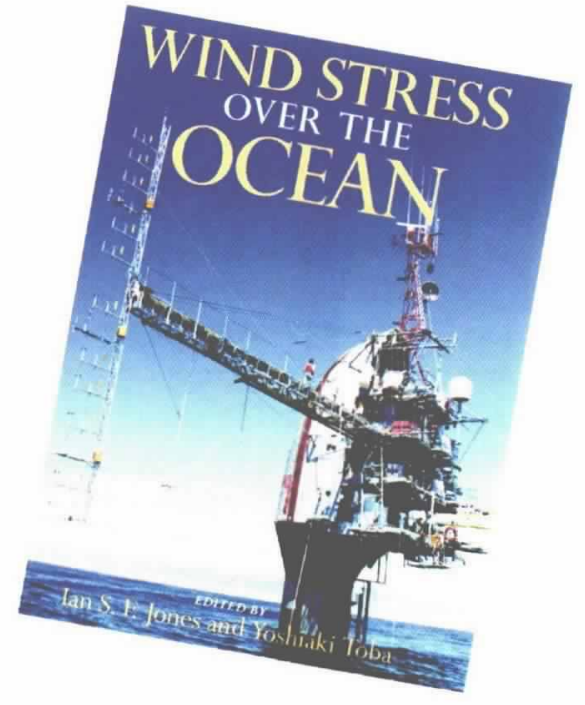

\section{Wind Stress Over the Ocean}

\author{
Edited by Ian S. F. Jones and Yoshiaki Toba \\ Cambridge University Press \\ 307 pp., ISBN: 0521662435

\section{Review by C.W. Fairall \\ NOAA Environmental Technology Laboratory \\ Boulder, Colorado USA}

The monograph is the final report of the Scientific Committee on Oceanographic Research (SCOR) working group 101 which was commissioned in 1993 to survey the state of knowledge and suggest where research might be directed on the topic of stress over the ocean. A team of experts was assembled at several workshops over the years and eventually this book was produced. The editors suggest this work should be viewed as a companion to an earlier SCOR monograph on Dynamics and Modeling of Ocean Waves (Komen et al., 1994). The book is divided into three parts: an overview; a part 1, which is 'concerned with basic issues of the dynamics related to the wind stress over the ocean' ; and a part 2, which 'deals with the uncertainties in parameterizing drag over the ocean' and 'describes issues of a more specific nature crucial in understanding the physics'. Part 1 contains six chapters; Part 2 contains eight chapters.

Part 1 begins with chapter 2, a discussion on historical drag coefficient expressions, culminating with a table listing of some 15 different expressions for roughness length. The newest formula is from 1992. A figure in the text shows all 15 expressions with a collection of laboratory and field data. This figure clearly shows why SCOR felt that this monograph was needed. Chapter 3 is a discussion of atmospheric and oceanic boundary layer physics. Turbulence closure, Ekman layers, the surface layer and similarity theory, and near-surface interactions (such as the stratifying effect of sea spray) are presented. Chapter 4 is on ocean wave spectra and integral properties. The equilibrium spectrum, short wind-waves, and the cutoff in the capillary range are discussed. This is followed by a complicated discussion of how long waves influence capillary waves. Chapter 5 is on drag mechanisms: flow patterns in air and water, pathways for momentum in the ocean, and breaker dynamics. Coupling mechanisms are presented in Chapter 6. This is essentially a discussion of the various terms in the wave spectrum budget equation. Models of the wave-induced stress and the implications for which wavelengths contribute to stress are discussed. This is followed by an unconventional but interesting representation of the flow profile that is specified from the atmosphere into the ocean. Part 1 is concluded with a discussion of measurement of stress: various instruments, analysis/processing techniques, and sources of error.

Part 2 begins with a discussion of the influence of swell on the drag. Observations from a wave tank, a lake, and the open ocean are shown. The effects of unsteadiness (i.e., usually changes in the wind speed or direction with time) are discussion in Chapter 9. Here deviations from an expected equilibrium wave field are linked to changes in the stress. In Chapter 10 Yuri Volkov summarizes numerous attempts to parameterize stress (or the drag coefficient) using wave age as the main parameter. A single analytical formula for the Charnock parameter is the final product. If you had to reduce this book to a single result, this would be it. Mesoscale effects are presented in Chapter 11. This refers to larger-scale boundary layer effects such as role vortices and other sources of variability such as storms, land-sea breeze systems, etc. Deviations of the stress vector from the mean wind vector are discussed in Chapter 12. The effects of surfactants on stress are presented in Chapter 13; the effects on stress come in through effects on the small-scale waves. Inhomogeneities such as fronts and current boundaries are discussed in Chapter 14. The subject is similar to Chapter 11 but the treatment is totally different with a lot of examples using aircraft and satellite measurements. The limits imposed by basin boundaries (through fetch limits on wave properties) are briefly presented in Chapter 15.

The editors of this book have certainly assembled an all-star cast but I can't say they have produced a glittering product. There is no question these guys know their stuff as well as anyone. Essentially all of the important ideas are here, but many of the attempts of synthesis were not successful. I found it difficult to see how some of the pieces fit together. Many important quantities are expressed in different ways in different chapters with little guidance on whether we are being quoted a particular obscure/favorite result or some kind of general conclusion. Strangely, Chapter 1 (the 
overview) is a complete failure. It is a collection of poorly described figures, some pulled from subsequent chapters and some not. I am not sure if it is supposed to be a synthesis of the book or background; either way, it is a disappointment. Given the material, it makes almost no sense to read the overview before reading the rest of the book. In my view, the figures and equations in the entire book would have benefited from at least one more round of careful editorial examination. One of my pet topics, the behavior of stress at hurricane wind speeds, was not really mentioned except briefly (and inadequately) in a discussion of the effects of sea spray.

These criticisms aside, there is a lot of useful material in this book. My personal favorite chapter is Huang, Toba, Shen, Klinke, Jahne, and Banner's discussion of ocean wave spectra. The introductory parts were beautifully written and filled with insights that made me feel like I was really getting the important stuff. The chapter on stress measurement by Larsen, Yelland, Taylor, Jones, Hasse, and Brown is also very good. Another plus is the massive reference list. On balance, though, I found the overall effort to be a bit disappointing.

\section{Books Undergoing Review:}

DEEP CUBA: The Inside Story of an American Oceanographic Expedition By Bill Belleville

University of Georgia Press, 288 pages ISBN 0-8203-2417-5

Oceans 2020: Science, Trends and the Challenge of Sustainability

Edited by J. Field, G. Hempel, and C. Summerhayes Island Press, 296 pages, ISBN 1-55963-470-7

Technology and Applications of Autonomous Underwater Vehicles Edited by Gwyn Griffiths

Taylor and Francis, London, 342 pages ISBN 0-415-30154-8

\section{Book Received for Review:}

Atmosphere-Ocean Interactions, Volume 1 Edited by W. Perrie

WIT Press, 312 pages, ISBN 1-85312-892-9

\section{UPCOMING EVENTS}

Oceanology International Americas June 4-6, 2003

Ernest N. Morial Convention Center New Orleans, Lovisiana www.oiamericas.com

\section{Ocean Research Conference Sponsored by TOS and ASLO February 15-20, 2004 Honolulu, Hawaii www.tos.org/2004Ocean ResearchConference.htm}

Oceans 2003 Celebrating the Past... Teaming for the Future September 22-26, 2003 Town \& Country Hotel and Convention Center San Diego, California www.mtsociety.org/conferences

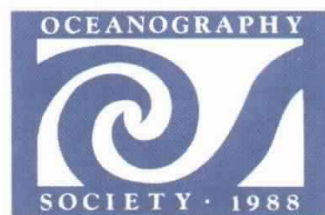

